\title{
Flux and flow
}

\author{
Christine Hawley
}

The apocalyptic fate of the subsurface dwellers in EM Forster's short story 'The Machine Stops' (Forster, 1909) and Thomas More's 'Utopia' (More, 2010) may portray scenarios of unparalleled difference, but both the fifteenth century and the nineteenth century writers were fired by an imagination about the future. The Forster cameo is one of foreboding, describing a catastrophe of unimaginable proportions where one might find parallels with the environmental cynics who portray scenarios of extreme flooding, extreme heat and cold that would leave communities decimated (Forster, 1909). By contrast, More's vision outlines a societal model of the future that addresses how to combat the social inequalities. His essay is prescient in that it understands profound social tensions that prove to be timeless. The answers he proposes take place on the island of Utopia where philosophically driven structures of governance and moral codes help to determine an ideal world (More, 2010).

Even if one's view is not as idealistic as More or as apocalyptic as Forster, it would be reasonable to assume that some measure of each is more likely than either in entirety, and that in this context we could ask the questions about the city of London and what it might be like, fifty years hence. What is undeniable is that the scenario planners must adopt a measured response to climate change, but designers must also think about the technological and socioeconomic adjustments that would influence behavioural patterns.

At this point in time it is difficult to establish data that can accurately pinpoint possible scenarios; environmental science offers, if not conflicting, then highly polarized evidence. The economic turbulence in the last century has failed to deliver models that facilitate better forecasting. The social and cultural shifts currently evident on a global scale may produce a new political order that none has anticipated. It is likely that in fifty years' time, much of the building fabric of the city will remain; however whether there will be sacrificial policies that benefit the historic or politically important, one can only speculate.

Scenario planning relies on considering a wide range of possibilities, some of it predicated on existing data which could be manipulated in a number of ways offering no one simple solution. The understanding and control of climate related issues are an inexact science, yet there will be both political and economic incentives to ensure that structures are insulated and stabilized. Much

How to cite this book chapter:

Hawley, C. 2013. Flux and flow. In: Bell, S and Paskins, J. (eds.) Imagining the Future City: London 2062.

Pp. 41-44. London: Ubiquity Press. DOI: http://dx.doi.org/10.5334/bag.e 
of the attention in the next fifty years will focus on existing building stock and infrastructure and how this might be safeguarded, but this will be selective; it would be wrong to assume that all structures are able to perform in an energy efficient manner. There will be those buildings that for historic and cultural reasons that will remain unaltered. The opportunities for designing and building new will be limited; there will be a requirement to utilize recycled materials and possibly the use of new composites that would create buildings with minimum hydrocarbon impact. The understanding of 'new' may become a completely altered concept.

Digital technology will have its impact on all aspects of life, from healthcare to education; from transportation to communication. The advances made, many already in trial, will have extraordinary impact and for many, will create unforeseen consequences. If we speculate that these changes could be serendipitous, how would this affect London and how would the architectural community prepare and respond? The current pattern of city use will be unrecognizable. Commuter traffic will significantly decline as transportation costs rise; commercial space will be redesignated, and there is the possibility that these premises could be re-colonised as dwellings. At the moment the dominance of the digital highway lies in informatics, yet it will only be a short time before all forms of fabrication are possible to control remotely. Therefore, let us speculate that the segregation of management, dwellings and production no longer exists. There are of course certain pragmatic issues, but the delineation of function geographically as we know it will no longer be relevant. If this happens, it will change the design agenda. Designers will become part of larger, integrated teams across the major disciplines, and the responsibilities that each will take may become unrecognizable.

If we consider some of the impact that environmental issues will have on London, the results will not only be architecturally pragmatic, but could also fundamentally alter the way we use the city. In fifty years, the concept of movement and why we need to move will have already been challenged; passenger travel could be airborne in vessels powered by inert gas. Notwithstanding the need to change the demand on fossil fuels for transportation, there is an argument to become much more radical in our thinking and not assume that road and rail travel will still be the backbone of our movement systems. A rise in water level might suggest the reopening of currently defunct waterways (both under and over-ground), and the increased use of existing water routes. There is a persuasive argument that indicates that the movement of heavy loads is done far more energy efficiently on water than on surfaces that create greater friction. It would not only be vessels that would change their energy source but the way we create energy would also be the function of London's waterways. Whatever advances are made in the science of harvesting alternative energy, the water courses of London will have a significant role harnessing energy in turbines through currents and tidal flow. The use of water-powered machinery at a micro level has been understood for centuries, and therefore the increase of micro hydropower would be feasible, even in domestic environments. The water tributaries will become critical pathways through the city, but these will also be used to develop new aquatic landscapes.

The supremacy of London parkland may give way to both public and private aquascapes that could both be used at a micro level for filtration, and as a new component in urban farming. Strategic and local groups will be implementing policies that encourage the use of open space for agricultural or aquatic cultivation. Data suggests that current farming practices will be economically unsustainable within fifty years, and it is for these and associated environmental reasons that farming within the city may become a reality. The image of the urban allotment has been a familiar picture since the interwar years; however the urban smallholding that farms meat and dairy produce has not yet become an established part of life. Within some new housing developments, it is arguable that the integration of a mixed farming unit is not implausible. During the winter months the animals would be kept indoors, and during the summer months they could get access to open rotational grazing in the existing parklands. The (treated) waste byproducts 
of such a system could be used to supplement the fertilizing requirements of conventional crops. To assume that all organic production would take place on horizontal surfaces is a limiting view; both new and existing buildings could be used to grow plants vertically using hydroponic systems. The production of organic material will become more incorporated into the fabric of the city and not just the agricultural plants we are currently familiar with, but autotrophic plants such as algae which will not only be used to create energy but also be used as a nutritional alternative to conventionally produced food.

The socioeconomic balance in fifty years' time has a number of unpredictable factors - the changing demographic and its cost to society, the reconfiguring of the workplace through digital advances and the nature of the manufacturing industries. The structures of communities are set to change. These structural shifts will have a fundamental effect on the ownership of property in the capital and perhaps, the way in which we conceptualise 'home'.

Prior to the first and second world wars, the housing stock barely moved in value; the destruction of the housing stock during the wars dramatically devalued the market. As such a high proportion of housing stock was rented there were particular pressures on landlords, who were often holding negative equity. Pre and inter-war tenancies were fixed and properties, if they were sold at all, were done so at a fraction of the cost of living index. What is interesting to reflect on - and perhaps a lesson for the future - is that at that time absolutely no one predicted the repeal of the 'Rent Act' and the enormous changes that were a result of this legislative decision: the social changes and modification of taxation law influenced a pre-capitalised market that precipitated significant rise in owner occupation. The model of housing may therefore radically change once again; the economic context will alter to challenge the traditional concept of owner occupation. If one were to link this together with mutable demographics and the rise of a dependent community, there would then be a requirement to design for extended family communities in central London.

There is a strange paradox, in that the enormous advances in technology and the sweeping fluxes of the economy could create patterns of living within the city that are akin to a historic model.

The physical vision of Forster predicts a society that must live beneath the surface of the earth as a result of the abuse of nature, and is finally annihilated when the technology that supports them fails [1]. The morality of this tale lies in the danger and power of human greed and the unconsidered consequences of technological advance. More's vision relies, more optimistically, on society's ability to organise communities of greater equality, where harmony comes through understanding that a multifaceted society benefits from interdependence rather than independence [2]. Perhaps we should reflect on the central themes of both and consider not only the physicality of our cities, but how technology, nature and governance will shape London in 2062.

\section{References}

Forster EM. 1909. The Machine Stops. UK: Oxford and Cambridge Review More T. 2010. Utopia. 3rd ed. WW Norton \& Co 

